Cukurova Üniversitesi Mühendislik Fakültesi Dergisi, 36(4), ss. 1089-1097, Aralık 2021

Cukurova University Journal of the Faculty of Engineering, 36(4), pp. 1089-1097, December 2021

\title{
Vardiyalı Çalışanların Gürültü Algı Yanılgısının İncelenmesi
}

\author{
Mehmet Zeki ACAR ${ }^{1}$ ORCID $0000-0001-9312-1431$ \\ Mehmet KARAKILÇIK ${ }^{* 2}$ ORCID 0000-0003-3659-3875
}

${ }^{1}$ Çukurova Üniversitesi, Fen Bilimleri Enstitüsü, İs Să̆llğg ve Güvenliği Anabilim Dall, Adana
${ }^{2}$ Çukurova Üniversitesi, Fen Edebiyat Fakültesi, Fizik Bölümü, Adana

Geliş tarihi: 01.06.2021 Kabul tarihi: 10.12.2021

Atıf şekli/ How to cite: ACAR, M.Z., KARAKILÇIK, M., (2021). Vardiyall Çalı̧̧anların Gürültü Algı Yanllgısının İncelenmesi. Çukurova Üniversitesi, Mühendislik Fakültesi Dergisi, 36(4), 1089-1097.

\section{$\ddot{\mathbf{O} z}$}

$\mathrm{Bu}$ çalışmada, vardiyalı çalışanların gürültü algısı yanılgıları araştırılmıştır. Bu amaçla, Sunar Grup bünyesindeki Sunar Misır Entegre Tesisleri kepek depolama ve ham yağ ünitesinde gece ve gündüz vardiyalarında çalışanların gürültü şiddeti algılama tepkileri belirlenmeye çalışılmıştır. Bunun için, gece ve gündüz vardiyalarında çalışanların gürültüye maruz kaldıkları otobüse biniş ve varıș noktalarında (dış ortam), ve kepek depolama ve ham yağ ünitesinde (iç ortam) gürültü şiddeti ölçümleri yapılmıştır. Çalışanların gündüz ve gece diş ortamda maruz kaldıkları farklı gürültü şiddetinin algı yanılgısına neden olduğu ve bunun çalışanlar üzerindeki olumsuz etkileri değerlendirilmiştir. Sonuç olarak, gece vardiyasında çalışanların dış ortamlar ile iç ortamlar arasındaki gürültü şiddeti farkı sırasıyla, 16,67 dB ve $15,67 \mathrm{~dB}$ 'lik gürültü şiddetini doğru algıladığı için kulaklıkla çalıştığ1 görülmüştür. Ancak, gündüz vardiyasında çalışanların gürültü şiddeti farkını yeteri kadar algılayamadıkları için kulaklık kullanmadan çalıştıkları belirlenmiştir. Bu nedenle özellikle gündüz vardiyası çalışanlarının, kulaklık veya kulak tıkacı ile kulaklarının korunması için gerekli tüm önlemler alınmalıdır. Ayrıca kapalı ortamda gürültüye neden olan taşıma helezonu, silo havalandırma fanları, pres ve kabuk soyma makineleri iyileştirilmeli veya yenileri ile değiştirilmelidir.

Anahtar Kelimeler: Vardiyalı çalışma, Gürültü, Gürültü algı yanılgısı, Kulak koruyucu

\section{Investigation of Noise Perception Misconception of Shift Workers}

\begin{abstract}
In this study, noise perception misconception of shift workers was investigated. For this purpose, it has been tried to determine the noise intensity perception response of the employees night and day shifts in the bran storage and crude oil unit of Sunar Misır Integrated Facilities within Sunar Group. For this, noise intensity measurements were made at the boarding the bus and arrival points (outdoor environment) and bran storage/crude oil unit (indoor environment) where those working in day and night shifts are exposed to noise. It has been evaluated that the different noise intensity that the employees are exposed to during the day and night in the external environment causes a false perception and the negative effects of this on the employees. As a result, it has been observed that night shift workers work with headphones because they correctly perceive the noise intensity differences between the outside environments and the indoor
\end{abstract}

*Sorumlu (Corresponding author) yazar: Mehmet KARAKILÇIK, kkilcik@cu.edu.tr 
environments, $16.67 \mathrm{~dB}$ and $15.67 \mathrm{~dB}$, respectively. However, it was determined that those working in the day shift could not perceive the difference in noise intensity sufficiently, so they worked without using headphone. For this reason, all necessary precautions should be taken to protect of the ears with earplugs or headphones, especially for day shift workers. In addition, conveying auger, silo ventilation fans, press and debarking machines that cause noise in the indoor environment should be improved or replaced with new ones.

Keywords: Shift work, Noise, Noise perception misconception, Ear protection

\section{GíRIŞ}

Sanayi Devrimi ile birlikte makinaların üretim alanına girmesiyle daha fazla üretim yapılmıştır. Daha fazla kazanmak için vardiyalı çalışma sistemine geçilmiştir. Böylece, Dünya'da büyük endüstri kuruluşları ile başlayan vardiyalı çalışma iş hayatında önemli bir mesai kavramı haline gelmiştir. Ancak, vardiyalı çalışma hayatı ile birlikte, özellikle iş sağlığı ve güvenliği (İSG) açısından yeni sorunlar ortaya çıkmıştır. Bunlar, fizyolojik, psikolojik ve sosyolojik olarak çalışanların sağlığını etkileyen etmenlerdir. İSG açısında bu sorunların çözülmesi için teknik ve yasal önlemlerin alınması bir zorunluluktur. Vardiyalı çalışmaların çalışanlar üzerinde oluşan fizyolojik etkiler, geçici veya sürekli işitme bozuklukları (kayıpları), kan basıncının artması, dolaşım bozuklukları, solunumda hızlanma, kalp atışlarında yavaşlama ve ani reflekslere yol açmaktadır. Psikolojik etkiler, davranış bozuklukları, aşırı sinirlilik ve aşırı tepkiler, hoşnutsuzluk, tedirginlik, streslerdir. Sosyolojik etkiler ise, aile ve sosyal yaşamı olumsuz etkilemesi ile aile içi huzurun ve sosyal iletişimin bozulmasıdır. Bu etkilerin çalışanların iş veriminin düşmesine, konsantrasyonun bozukluğuna, hareketlerinin yavaşlamasına, dinlenmesinin bozulması gibi birçok sağlık sorunlarına yol açtığı birçok araştırmacılar tarafından belirtilmiştir [1-5].

Vardiyalı çalışmalarda özellikle gece vardiyasında çalışanların psikolojik, sosyal açıdan fiziksel ve duygusal olarak olumsuz etkilendiğini tespit edilmiştir [6]. Ancak, vardiyalı çalışmanın günümüzde, artan talep yüzünden kaçınılmaz bir çalışma sistemi haline geldiğini belirtilmiştir. Aselsan'daki vardiyalı çalışanlar fizyolojik ve psikolojik olarak incelenmiş ve bazı çalışanlarda birtakım kardiyovasküler ve sindirim sistemi semptomları gözlenmiştir [7]. Vardiyalı çalışma sisteminin çalışanlar üzerinde sadece psikolojik ve sosyolojik olarak değil aynı zamanda fizyolojik olarak sağlık üzerinden birçok farklı etkisi olduğu görülmüştür. Ayrıca, çalışanların sağlık, güvenlik ve sosyal açıdan iyilik halinin de olumsuz etkilendiği saptanmıştır [8]. Vardiyalı çalışanlar içinde de gece vardiyası çalışanlarında uyku bozukluğu nedeniyle parasomni görülme sıklığının gündüz vardiyasında çalışanlara göre daha fazla olduğu görülmüştür [9].

Çalışanların üretim eylemine paralel olarak karşılaştığı tehlike ve riskler gün geçtikçe farklılık göstermektedir. Değişen risklere karşı alınması gereken önlemler gün geçtikçe çeşitlilik kazanmaktadır. Gelișen endüstrileşme ve teknolojik gelişmeler neticesinde günümüzde potansiyel risklere karşı yeni ISG önlemlerinin alınması gerekmektedir [10]. Özellikle, vardiyalı çalışan bireylerin sağlıklı beslenme eğitimleri almaları, beslenmelerinin bir diyetisyen tarafindan düzenlenmesi ve kronik hastalıklara karş1 koruyucu önlem alınması ve uyku kalitelerinin artırılmasının önemli olduğu görülmüştür [11]. Vardiyalı ve vardiyasız çalışan işçilerin depresyon, anksiyete ve stres durumlarını etkileyen faktörlerin çalışanların sağlığını olumsuz etkilemektedir [12]. Sivas Cumhuriyet Üniversitesi Araştırma ve Uygulama Hastanesi ve Sivas Numune Hastanesi'nin tüm birimlerinde, gece vardiyasında (16:00-08:00 saatleri arasında) çalışan hemşirelerin meme kanseri risk düzeyi ile uyku kalitesi arasında ilişki olduğunu saptanmıştır [13]. Vardiyalı sistemde çalışanların uyku düzenlerinde meydana gelen düzensizliğin kurum içinde iş tatmini, uyku kalitesi ve hijyen, ve iş doyumu ile uyku kalitesi arasında ilişki olduğu görülmüştür [14]. 
Son yıllarda yapılan birçok bilimsel çalıșmalarda vardiyalı çalışmaların çalışanlar üzerinde birçok olumsuz etkileri belirtilmiştir. Ancak, fiziksel etmenlerden birisi olan gürültü şiddetinin vardiyalı çalışmalarda çalışanlar üzerinde bıraktığı algının davranışsal etkisinin daha önce incelenmemiş olması motivasyonumuzda önemli enerji kaynağı olmuştur.

Bu çalışmalar 1şığında, önemli fiziksel etmenlerde birisi olan gürültünün, farklı ortamlarda farklı düzeylerde algılanmasının vardiyalı çalışanlar üzerinde oluşturduğu algı yanılgısının İSG açısında etkisi incelenecektir. Bunun için, "Tehlikeli Sınıfta" bulunan bir Entegre Endüstriyel Yağ Sanayi'de yapılan vardiyalı çalışmalarda gündüz ve gece vardiyasında çalışanların dış ortam ve iç ortam arasındaki gürültü farkını algılama düzeylerine göre verdiği davranışsal tepkileri gözlemlenecektir. Bu amaçla, vardiyalı çalışanların servise bindikleri ortam (dış ortam) ve tesiste çalışacakları bölümlerden olan kepek deposu ve ham yağ ünitesi (iç ortam) arasındaki gürültü farkının çalışanlar üzerinde oluşturdu algı belirlenecektir. Algilama sorununun kaynaklanan aşırı gürültü kaynaklı riske karşı kulak koruyucu (kulaklık) kullanımına olan hassasiyetleri belirlenmeye çalışılacaktır. Elde edilen bulgulara göre, gürültünün oluşturabileceği risklerinin bertaraf edilmesi için alınabilecek önleyici ve düzeltici tedbirlerin alınması sağlanacaktır. Ayrıca, gürültülü ortamlarda yapılan çalışmalarda, farklı gürültülü ortamların çalışanlar üzerindeki alg1 yanılgısına dikkat çekilecektir. İSG talimatlarına göre çalışanların kulaklık kullanmaları önerilecektir.

\section{MATERYAL VE METOT}

İşyerlerinde insan sağlığını olumsuz etkileyebilecek Fiziksel Risk Etmenleri (FRE); Gürültü, titreşim, termal konfor, aydınlatma, iyonize-noniyonize ışın, alçak ve yüksek basınç gibi fiziksel etkilerdir. İşyerlerindeki iş yapma ortamlarında çoğunlukla makinalar ile iş yapılmaktadır. Çalışanlar iş yaptıkları bu makinalarla birlikte aynı ortamda bulunmak zorundadır. 6331 sayılı kanuna bağlı yönetmelikte "Çalışanların Gürültü İle İlgili Risklerden Korunmalarına Dair Yönetmelikte" makinaların çıkardığı gürültünün en düşük maruziyet eylem değeri olan 80 dB'yi geçmemesi istenir. Ancak, bazı makinaların çıkardığ gürültünün en yüksek maruziyet eylem değeri olan 85 dB'in üzerine gürültü kaçınılmazdır [15].

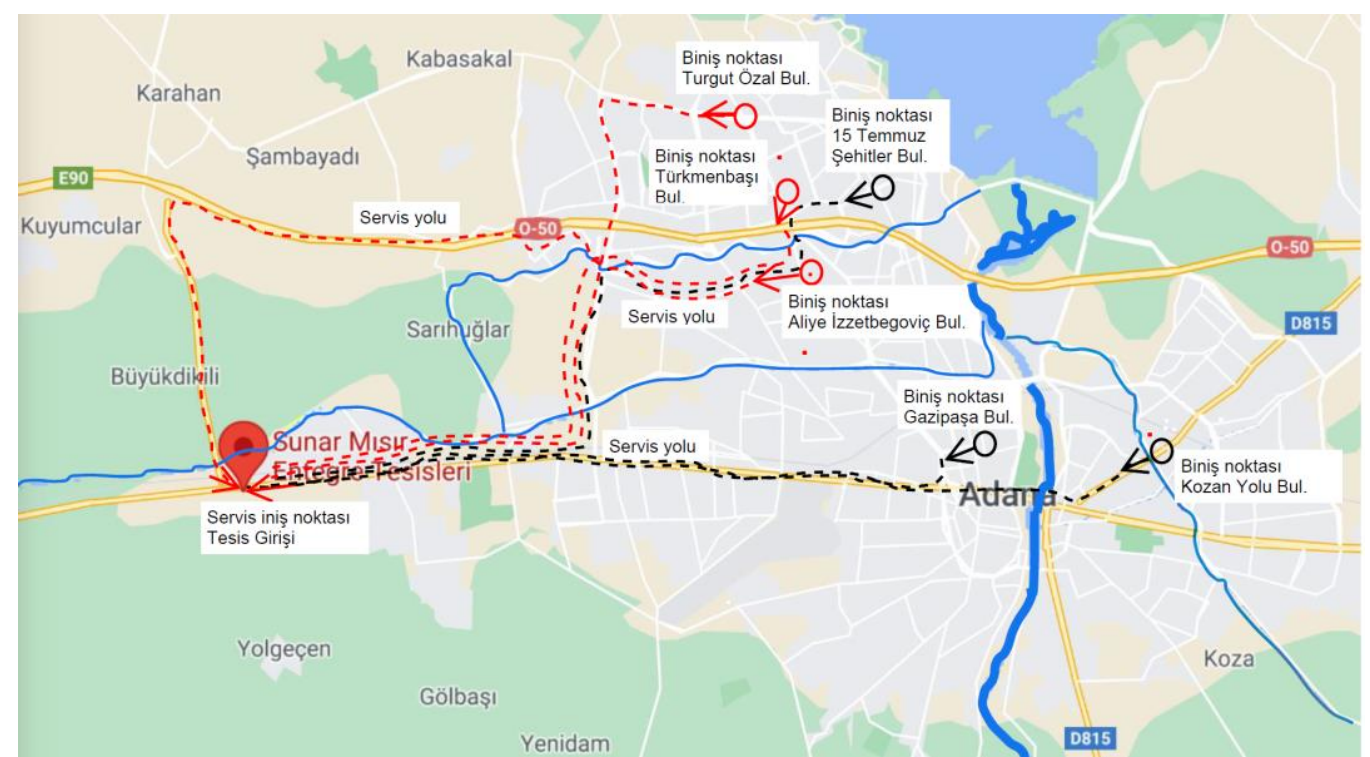

Şekil 1. Çalışanların servis aracı biniş-iniş noktaları ve hareket hattı [17] 
$\mathrm{Bu}$ durumda, "Kişisel Koruyucu Donanımların İşyerlerinde Kullanılması Hakkında Yönetmelik" belirtildiği üzere, yüksek gürültülü ortamlarda çalışanların "Kişisel Koruyucu Donanımı (KKD)" olan kulaklıkla çalışması istenir [16].

Şekil 1'de, Adana ili Seyhan İlçesinde yer alan Sunar Misır Entegre Tesisleri Sanayi kepek deposu çalışanların servise biniş noktası $(\mathbf{O} \rightarrow)$ ve hareket doğrultusu (----), ham yağ ünitesi çalışanların servise biniş noktası $(\mathrm{O} \rightarrow)$ ve hareket doğrultusu (----) servisten iniş noktası (tesis girişi) servis hareket haritası üzerinde verilmiştir. Çalışanların çalışma ortamları kepek deposu ve ham yăg ünitesidir.

Vardiyalı çalışanların servis yolculuğu süresi gündüz ve gece vardiyaları için sırasıyla 25 ve 20 dakikadır.

Gündüz ve gece vardiyası çalışanları çalışma ortamlarına ulaşıncaya kadar şehir içi gürültüye maruz kalmaktadır. Bu gürültü, yolculuk süresi boyunca çalışanlar üzerinde bir gürültü algısı oluşturmaktadır. Çalışanların iş yaptıkları çalışma ortamı olan kepek deposu ve ham yağ ünitesi ise farklı bir gürültülü ortamdır.

Şekilde 2'deki ürün akış şemasında görüldüğü gibi, mısır ürünü Ünite 1 (lift) den gelir ve misır taşıma helezonlarla Ünite 2'deki siloya aktarılır. Ürün buradan helezonlarla Ünite 3'deki Masarasyon'a geçer. Burada kükürtlü sıcak suya 48 saat maruz kalan mısır tanesi parçalanacak kıvama kadar şiştikten sonra Ünite 4'deki Millhouse'daki değirmenlerde kırılır. Kırılan mısır tanelerinin içindeki yağlı öz konveyörlerle ham yağ bölümüne gönderilirken, geriye kalan nişasta sütü glikoz ünitesine enzimlere maruz kaldıktan sonra glikoz yapılmak üzere gönderilir. Misır tanesinden kalan kabuk kısmı ise, Ünite $5^{\text {'te }}$ kurutularak Ünite 6'daki taşıma helezonları vasıtasıyla Ünite 7'deki kepek deposuna iletilir. Bu işlemlerin yapılmasında kapalı ortamda birçok elektrik makinaları çalışmaktadır. Bu makinaların her birisi bir gürültü kaynağıdır. Ham yă̆ ünitesinde bulunan Millhouse değirmeninde mısırın kırılması ile ayrıştırılan mısır özü mekanik kırıma uğramak üzere silindirlerden geçirilir ve misır özünde bulunan ve elde edilmesi istenen ham yağın yaklaşık \%73'lük kısmı çıkarılarak rafineri ünitesine gönderilir. Kalan küspe ekstraksiyon tesisine gönderilir. Tüm bu işlemlerin yapılmasında kapalı ortamda birçok makine çalışmaktadır. Bunların her birisi bir gürültü kaynağıdır.

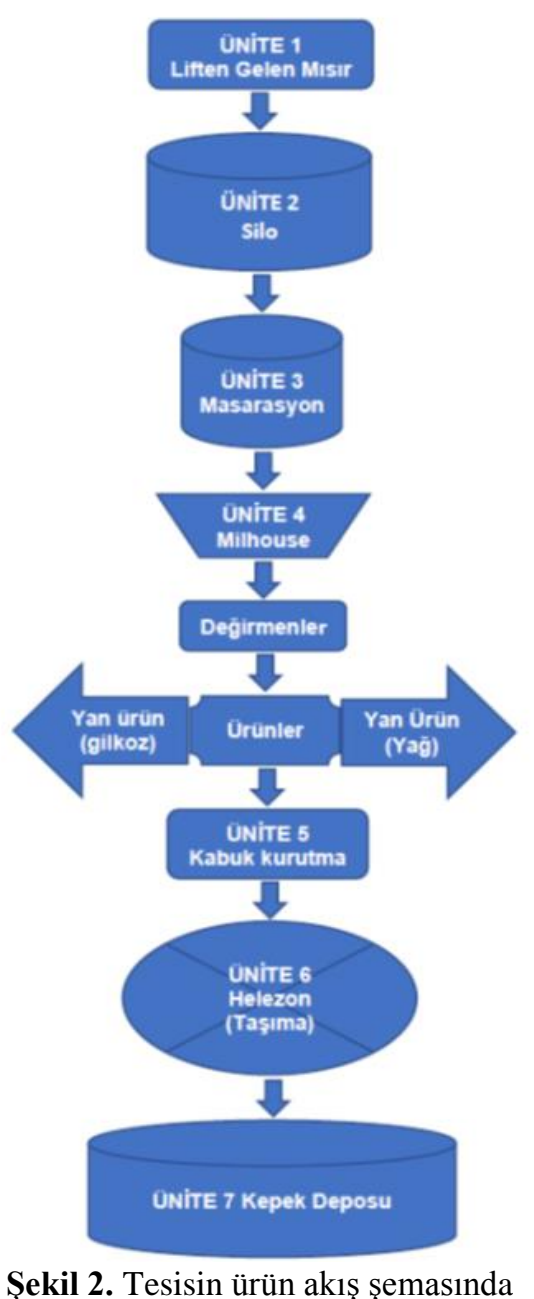

Gürültü ölçümünde kullanılan elektronik cihaz olarak Şekil 3'deki "PCE-MSM 4" gürültü ölçüm cihazı kullanılmıştır. Gürültü ölçüm cihazının hassasiyeti $4 \pm 1,4 \quad \mathrm{~dB} \quad$ dir. Yüksek hassasiyet/görüntüleme için $\mathrm{A}$ ve $\mathrm{C}$ frekans değerlendirmesi ve 4 haneli LCD ekranına sahiptir [18]. 


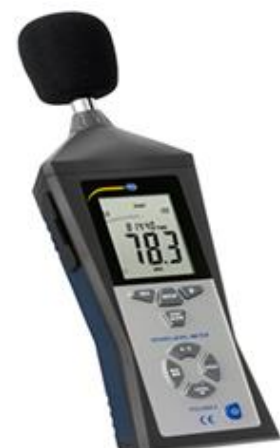

Şekil 3. Gürültü ölçüm cihazı [18]

Farklı ortamların gürültü şiddetinin çalışanlar üzerinde oluşturduğu gürültü alg1 yanılgısının çalışanların davranışları üzerindeki etkisini belirlemek için servise bindikleri ve indikleri noktalarda ve çalışma ortamlarında gündüz ve gece gürültü ölçümleri yapılacaktır. Gürültünün çalışanlar üzerinde oluşturduğu alg1 yanılgısını belirlenmeye çalışılacaktır. Böylece, çalışanların gürültüye karşı algı durumlarından kaynaklanan sorunlar belirlenecek ve çalışanların gürültüden korunması için gerekli önlemler daha etkin bir şekilde alınabilecektir. Bu çalışmada, ölçümler her bir çalışanın farklı vardiya da görev alacağı süre göz önüne alınarak 30 günlük bir süre içerisinde yapılmıştır. Böylece, bir entegre endüstriyel tesis içinde bulunan birimlerde çalışanların gürültü alg1 yanılgısı belirlenerek gürültü kaynaklarının risk oluşturmadan bertaraf edilmesi mümkün olabilecektir.

\section{BULGULAR VE TARTIŞMALAR}

Türkiye'de ve Dünya'da büyüyen gıda ihtiyacı ve doğal katkı maddelerinin yetersiz kalması endüstriyel gıda ihtiyacının doğmasına sebep olmuş ve endüstriyel gida zamanla toplumun vazgeçilmezi haline gelmiştir. Günlük üretimin artırılması için iş saatlerinin de artırılması yoluna gidilmiştir. Üretimin artırılması için vardiyalı çalışmaların yapılması bir zorunluluk haline gelmiştir. Özellikle tehlikeli sınıftaki endüstriyel sanayilerde iş yoğunluğu ve vardiyalı çalışmalardan kaynaklanan olası iş sağlığ 1 ve güvenliği riskleri ve nedenlerinin incelemesinin önemli hale gelmiştir.
Önceki çalışmalarda, vardiyalı çalıșmalardan kaynaklanan birçok fizyolojik ve psikososyal risklerin çalışanlar üzerindeki olumsuz etkilerinden bahsedilmiştir. Ancak, gündüz ve gece vardiyalarında yapılan çalışmalarda gürültü kaynaklı risklerin değerlendirmesinde, çalışmalar tarafından gürültünün tam olarak algılanamaması sonucu ortaya çıkan gürültü alg1 yanılgıs1 nedeniyle kulak koruyucularını (kulaklık) kullanmadıkları gibi bazı sorunları da beraberinde getirdiği görülmüştür.

Önemli bir entegre endüstriyel kuruluş olan ve "Tehlikeli Sınıfta" yer alan bir işyeri olan Entegre Sunar Misır Sanayi Tesisi'nde en az "B sınıfi" İş Sağlığı ve Güvenliği (ISSG) uzmanları çalışabilir. Tesis kendi İş Sağlığı ve Güvenliği Birimi (İSGB)'yi kurmuştur. Bu birimde kadrolu olarak, bir işyeri hekimi, bir sağlık personeli, bir A, üç B sınıfı ve 3 ISSG teknikeri olmak üzere toplam 9 İSG profesyoneli bulunmaktadır. Tesisin önemli bölümlerinden olan kepek deposu ve ham yağ ünitesinde 3 vardiya çalışmalar yapılmaktadır. Bu nedenle, kepek deposu ve ham yağ ünitesinde gündüz veya gece vardiyalarının her biri 7,5 saattir. Mesai boyunca gürültüye mazur kalan çalışanlar için bazı değerlendirme yapılmıştır.

Kepek deposu ve ham yağ ünitesinde vardiyalarında çalışanların gürültüye karşı alg1 yanılgısını belirlemek için gündüz ve gece vardiyaları için çalışanların servise bindikleri 3 ana arter ve fabrika girişlerinde gündüz ve gece olmak üzere gürültü ölçümleri yapılmıştır [18].

Çizelge 1. Kepek deposu çalışanlarının servise biniş noktaları gürültü şiddeti

\begin{tabular}{|l|c|c|}
\hline \multirow{2}{*}{ Biniş noktası } & \multicolumn{2}{|c|}{ Gürültü şiddeti (dB) } \\
\cline { 2 - 3 } & Gündüz & Gece \\
\hline Turgut Özal Bulvarı & 78,6 & 69,7 \\
\hline Türkmenbaşı Bul. & 77,4 & 68,8 \\
\hline Aliya İzzetbegoviç Bul. & 77,1 & 68,3 \\
\hline
\end{tabular}

Çizelge 1'de kepek deposu çalışanlarının 3 farklı servise biniş noktası için yapılan ölçümlere göre, en yüksek gürültülü servise biniş noktasının gündüz için 78,6 dB ve gece için $69,7 \mathrm{~dB}$ ile Turgut Özal Bulvarı olarak belirlenmiştir. 
Çizelge 2. Ham yağ ünitesi çalışanlarının servise biniș noktaları gürültü şiddeti

\begin{tabular}{|l|c|c|}
\hline \multirow{2}{*}{ Biniş noktası } & \multicolumn{2}{|c|}{ Gürülttü şiddeti (dB) } \\
\cline { 2 - 3 } & Gündüz & Gece \\
\hline 15 Tem. Şehitleri Bul. & 77,9 & 69,6 \\
\hline Gazipaşa Bulvarı & 78,9 & 67,5 \\
\hline Kozan Yolu & 78,1 & 71,3 \\
\hline
\end{tabular}

Çizelge 2'de, ham yağ ünitesi çalışanlarının 3 farklı servise biniş noktası için en yüksek gürültü, servise biniş noktasında, gündüz $78,9 \mathrm{~dB}$ ile Gazipaşa Bulvarı ve gece ise $71,3 \mathrm{~dB}$ ile Kozan Yolu olduğu belirlenmiştir.

Şekil 4'de kepek deposu, işçi servisi biniş ve iniş (fabrika girişi) noktalarının gündüz ve gece gürültü şiddeti değerleri verilmiştir. Çalışanların gündüz ve gece maruz kaldığı ortalama gürültü şiddeti, servise biniş noktasında sırasıyla, 77,7 ve 68,93 $\mathrm{dB}$, fabrika girişinde sırasıyla 78,70 ve $71,50 \mathrm{~dB}$ ve ham yağ deposunda ise 86,70 ve $85.60 \mathrm{~dB}$ olarak ölçülmüştür.

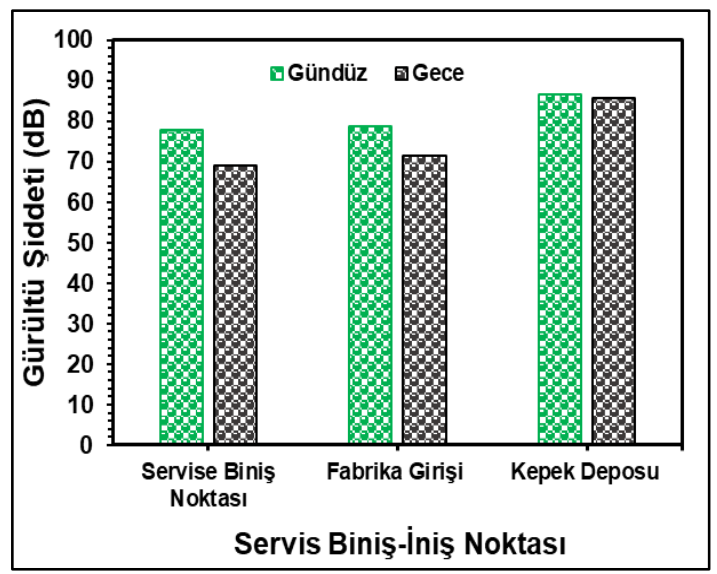

Şekil 4. Kepek deposu çalışanlarının maruz kaldığı gündüz-gece gürültü şiddeti dağılımı

Şekil 5'de ham yağ ünitesi, işçi servisi biniş ve iniş (fabrika girişi) noktalarının gündüz ve gece gürültü şiddeti değerleri verilmiştir. Çalışanların gündüz ve gece maruz kaldığ 1 ortalama gürültü şiddeti, servise biniş noktasında sırasıyla, 78,3 ve $68,47 \mathrm{~dB}$, fabrika girişinde sırasıyla 78,70 ve $71,5 \mathrm{~dB}$ ve ham yağ deposunda ise 86,80 ve 85,60 dB olarak ölçülmüştür.

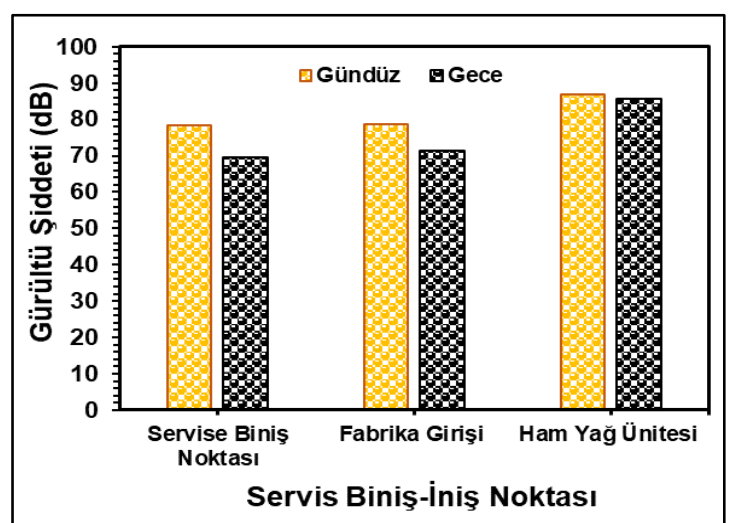

Şekil 5. Ham yağ ünitesi çalışanlarının maruz kaldığ1 gündüz-gece gürültü şiddeti dağılımı

Şekil 4 ve 5'de gürültü şiddetinin gündüz ve gece birbirinden farklı şiddetlerde olduğu görülmüştür. $\mathrm{Bu}$ farkların gündüz ham madde alımı gerçekleştiği için kepek deposuna ve ham yağ ünitesine yakın alanlarda ağır tonajlı araçlardan oluşan vasıta trafiği ve tesisin yakınında bulunan şehirlerarası karayolu trafiğindeki artıştan kaynaklandığ 1 belirlenmiştir.

Şekil 6'da ham yağ ünitesi ve kepek deposunun gündüz ve gece gürültü şiddetleri karşılaştırılmıştır. Kepek deposu ve ham yağ ünitesi ortalama gürültü şiddeti değişimi sırasıyla, gündüz için $86,7 \mathrm{~dB}$ ve $85,6 \mathrm{~dB}$ ve gece için 86,8 $\mathrm{dB}$ ve $85,6 \mathrm{~dB}$ olarak ölçülmüştür. $\mathrm{Bu}$ değerlerin en düşük ve en yüksek maruziyet eylem değerlerinin çok üstünde oldukları tespit edilmiştir.

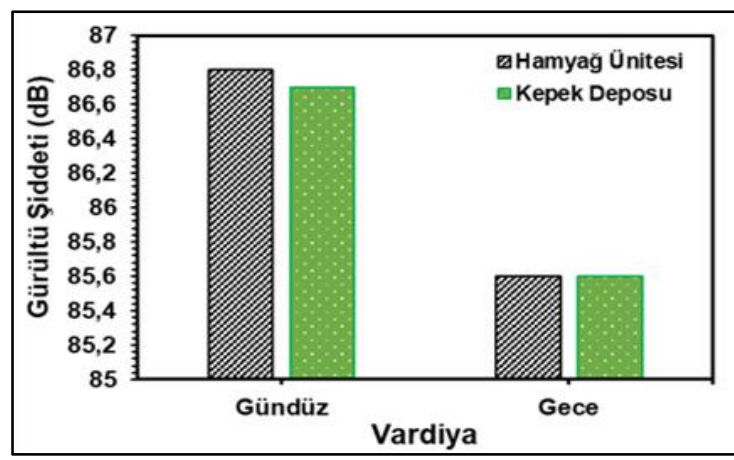

Şekil 6. Ham yă̆ ünitesi ve kepek deposunun gündüz-gece vardiyası için gürültü şiddeti dağılımı 
Şekil 6'da ham yağ ünitesi ve kepek deposunun gündüz ve gece için gürültü şiddetinin birbirinden farklı şiddetlerde olduğu belirlenmiştir. Gündüz fabrika içinde kepek deposuna yakın bir bölge civarından ham madde alımı için ağır tonajlı araçlardan oluşan vasita trafiğinden kaynaklandığı belirlenmiştir. Ayrıca, tesisinin yakınında bulunan şehirlerarası karayolundaki trafik artışın gündüz gürültü şiddetinin artmasına neden olduğu görülmüştür. Dolayısıyla, gündüz fabrika içindeki trafik artışı ile ortamda ki gürültü şiddeti seviyesi artarken gece hammadde alımı yapılmadığı için gürültü şiddeti de önemli bir şekilde azalmaktadır. Bununla birlikte, ham yağ ünitesi yakınında bulunan karayolu araç trafiğinin de azalması ile gürültü şiddeti fabrika içinde önemli ölçüde azalmaktadır. Gündüz-gece gürültü şiddetinin çalışanların bindikleri ve indikleri fabrika girişindeki $80 \mathrm{~dB}$ sınırın altında kaldığı ve işçiler için risk oluşturmadığı belirlenmiştir. Ancak, ham yağ ünitesinde gündüz gürültü şiddetinin $86,8>85 \mathrm{~dB}$ ve gece ise $85,6>85 \mathrm{~dB}$ 'lik ile en yüksek maruziyet eylem değerinde olduğundan çalışanların sağlığı üzerinde ciddi bir risk oluşturduğu tespit edilmiştir. Çünkü, bu gürültü "Çalışanların Gürültü İle İlgili Risklerden Korunmalarına Dair Yönetmelikte" belirtilen 80/85 dB'lik en düşük/en yüksek sınır mazuriyet değerlerinin çok üstünde olduğu için çalışanların sağlığını olumsuz şekilde etkileyen bir gürültü şiddetidir. Gündüze göre, gece gürültü şiddetinin azalmasının nedeninin şehir içi trafiği ve diğer gürültü kaynaklarının azalmasından kaynaklandığ saptanmıştır.

\section{SONUÇLAR}

$\mathrm{Bu}$ çalışmada, işyeri İSG sınırları içerisinde sayılan bazı önemli ortamlarda gürültü ölçümleri yapılmıştır. Bir endüstriyel tesiste vardiyalı çalışmaların yapıldı ğı "kepek deposu" ve "ham yağ ünitesi” için gündüz ve gece vardiyasında çalışanların gürültü algı yanılgısı belirlenmiştir. Gürültü alg1 yanılgısına neden olan sorunlar tespit edilmiştir. Ayrica, endüstriyel gürültünün çalışanlar üzerinde sadece işitme kaybına yola açmadığı aynı zamanda fizyolojik ve psikolojik risklerin iş performansını da olumsuz etkilediği ve çalışların yüksek gürültüye maruz kalması sonucunda, kişide zamanla konuşma ve iletişim bozukluğu gibi kalıcı bir işitme kaybına yol açabileceği görülmüştür. Gürültüye bağlı işitme kaybı, kümülatif bir süreçtir. İşitme kaybını belirleyen faktörler arasında genel gürültü seviyeleri, gürültünün bileşimi, tipik bir iş günü boyunca maruz kalma süresi ve çalışanın çalışma geçmişi yer alır. Gürültüye bağlı işitme kaybı, maruz kalan kişilerde rastgele meydana gelir. Bazı kişiler, gürültüye bağlı işitme kaybına diğerlerinden daha duyarlıdır. Kalıcı işitme kaybı, belirli iç kulak yapılarının hasar görmesinden kaynaklanır. $\mathrm{Bu}$ hasar tamir edilemez ve kalıcı olabilir.

$\mathrm{Bu}$ çalışmalardan elde edilen sonuçlar 1şığında öneriler ise şunlardır:

- Tespit edilen gürültülü ortamlarla ilgili değişen koşullar ve çalışma şartlarına uygun olarak işverenin ortam ölçümlerini yaptırması ve ortam koşullarına uygun tedbirlerin alınmasını sağlamalıdır.

- İşitme kaybı, gürültü şiddeti ve gürültüye maruz kalma süresine bağlı olarak değişir. Gürültülü ortamlarda çalışanların yıllık olarak yapılan odyometrik testlerinin sonuçları incelenerek çalışanların eşik kayması desibel (dB) olarak ölçülerek işitme kaybı belirlenmelidir.

- Çalışanların işitme kaybında herhangi bir değişiklik varsa çalışanlar fark etmeden önce değişiklikler tespit edilmelidir.

- Erken teşhis, çalışanlar üzerinde daha fazla hasar oluşmadan önce işyerinde değişikliklerin başlatılmasına yardımcı olabilir.

- Gündüz ve gece vardiyalarında önemli risklerden biri olan gürültü ilgili işveren tarafindan gürültüyü kaynağında yok edecek önlemler alınmalıdır.

- Gürültüyü kaynağında yok etmek mümkün değil ise ikame yani, daha az riskli olan teknoloji ile değiştirilmelidir. 
- İkame mümkün değil ise mühendislik önlemleri alınmalıdır. Eğer, bu mümkün değil ise toplu korunma önlemleri alınmalıdır.

- Kepek deposu ve Ham yă ünitesinde çalı̧̧anların mutlaka kulak koruyucusu olarak kulaklık takması sağlanmalıdır [15].

- Yukarıda belirtilen hususların hiçbiri yapılamıyor ise çalışanlara ortamdaki gürültü riskine uygun, "Kișisel Koruyucu Donanım (KKD)" kullanması sağlanmalıdır [16].

- Ayrıca, alınan tedbirlerin uygulanması için bir kontrol mekanizması oluşturulmalıdır.

- Gece ve gündüz vardiyalarında ilgili gürültülü bölümlere özgü gürültünün insan sağlığ üzerindeki oluşturacağ 1 olumsuz etkileri konusunda işe başlamadan önce uyarı niteliğinde çok kısa işbaşı eğitim programı yapılmalıdır [19]. Ayrıca, mevcut riskler ile ilgili verilen eğitimler afişler ve eğitici videolar ile desteklenmelidir.

\section{TEŞEKKÜR}

$\mathrm{Bu}$ çalışmanın tesislerinde yapılmasına izin veren Sunar Grup bünyesindeki Sunar Misır Entegre Tesisleri Yönetimine Yazarlar teşekkür eder.

\section{KAYNAKLAR}

1. 6331 Sayılı İş Sağlığı ve Güvenliği Kanunu, 2012. Resmi Gazete Sayıs1: 28726.

2. Ferri, P., Guadi, M., Marcheselli, L., Balduzzi, S., Magnani, D., Di Lorenzo, R., 2016. The Impact of Shift Work on the Psychological and Physical Health of Nurses in a General Hospital: A Comparison Between Rotating Night Shifts and Day Shifts. Risk Management and Healthcare Policy, 9, 203-211.

3. Dodia, P., Parashar, N., 2020. Shift-work Job Stress, Psychological Distress, and Job Satisfaction Among Employees. International Journal of Indian Psychology, 8(3), 1215-1223.

4. Vogel, M., Braungardt, T., Meyer, W., Schneider, W., 2012. The Effects of Shift Work on Physical and Mental Health. J Neural Transm, 119, 1121-1132.
5. Chao, P.C., Juang, Y.J., Chen, C.J., Dai Y.T., Yeh, C.Y., Hu, C.Y., 2013. Combined Effects of Noise, Vibration, and Low Temperature on the Physiological Parameters of Labor Employees. Kaohsiung Journal of Medical Sciences. 29(10), 560-567.

6. Selvi, Y., Özdemir G.P., Özdemir, O., Aydin, A., Beşiroğlu, L., 2010. Sağlık Çalışanlarında Vardiyalı Çalışma Sisteminin Sebep Olduğu Genel Ruhsal Belirtiler ve Yaşam Kalitesi Üzerine Etkisi. Düşünen Adam Psikiyatri ve Nörolojik Bilimler Dergisi, 23, 238-243.

7. Koçak, E.B., 2014. Aselsan'ın Vardiyalı Çalışma Sisteminin Fiziksel, Psikolojik ve Dikkate Dayalı Performans Kriterleri Üzerindeki Etkileri. Yüksek Lisans Tezi, Ortadoğu Teknik Üniversitesi, Fen Bilimleri Enstitüsü, Endüstri Mühendisliği, Ankara, 159.

8. Sevindik, D., 2016. Vardiyalı Çalışmada İş Sağlığı ve Güvenliği. Yüksek Lisans Tezi, Yıldırım Beyazıt Üniversitesi, Sağlık Bilimleri Enstitüsü, İş Sağlığı ve Güvenliği Ana Bilim Dalı, Ankara.

9. Gök, D.K., 2017. Vardiyalı Çalışanlarda Uyku Kalitesi ve Parasomni Sıklığı. Uzmanlık Tezi, Çukurova Üniversitesi, Tıp Fakültesi, Nöroloji Ana Bilim Dalı, Adana.

10. Akeloğlu, S., 2018. Vardiyalı Çalışanların İş Sağlığı ve Güvenliği Bilinç Düzeylerinin Ölçülmesi ve Bir Gıda Fabrikasındaki İyi Uygulama Teknikleri. Yüksek Lisans Tezi, Çukurova Üniversitesi Fen Bilimleri Enstitüsü. Endüstri Mühendisliği Ana Bilim Dalı, Adana.

11. Kırtız, G., 2018. İşçilerin Vardiyalı ve Vardiyasız Sistemde Çalışmasının Beslenme Durumu Üzerine Etkisi. Yüksek Lisans Tezi, Okan Üniversitesi, Sağlık Bilimleri Enstitüsü, Beslenme ve Diyetetik Ana Bilim Dal, İstanbul.

12. Boğurcu, H., 2019. Vardiyalı ve Vardiyasız Çalışan İşçilerin Depresyon, Anksiyete ve Stres Durumları ile Etkileyen Faktörlerin Karşılaştırılması. Yüksek Lisans Tezi, Ege Üniversitesi Sağlık Bilimleri Enstitüsü, Halk Sağlığı Ana Bilim Dalı, İzmir.

13. Çetin, İ.A., 2019. Gece Vardiyasında Çalışan Hemşirelerin Meme Kanseri Risk Düzeyi ve Uyku Kalitesi Arasındaki İlişkinin Belirlenmesi. Yüksek Lisans Tezi, Sivas 
Cumhuriyet Üniversitesi, Sağlık Bilimleri Fakültesi, Cerrahi Hastalıkları Hemşireliği Ana Bilim Dalı, Sivas.

14. Bağır, A., 2019. Vardiyalı Çalışanlarda Uyku Sorunları ve İş Tatmini Arasındaki İlişkinin İncelenmesi. Yüksek Lisans Tezi, Van Yüzüncü Y1l Üniversitesi, Sağlık Bilimleri Enstitüsü, Psikiyatri Anabilim Dalı, Van.

15. Çalışanların Gürültü ile İlgili Risklerden Korunmalarına Dair Yönetmelik, Resmi Gazete: 28.07.2013/28721.

16. Kişisel Koruyucu Donanımların İşyerlerinde Kullanılması Hakkında Yönetmelik, Resmi Gazete: 02.07.2013/28695.

17. www.google.map (Erişim tarihi: 5.5.2021)

18. www.pce-instruments.com (Erişim tarihi: 20. 02.2021)

19. Acar, M. Z., 2021. Bir Endüstriyel Sanayide Vardiyalı Çalışmalarda İş Sağlığı ve Güvenliğinin İncelenmesi. Yüksek Lisans Tezi, Çukurova Üniversitesi Fen Bilimleri Enstitüsü, İş Sağlığı ve Güvenliği Anabilim Dalı, Adana 
